\title{
Gambaran Self Directed Learning Readiness (SDLR) pada Mahasiswa Tingkat Pertama Program Studi Pendidikan Dokter di Fakultas Kedokteran Universitas Sam Ratulangi
}

\author{
Arselina C. Mandolang
}

Program Studi Pendidikan Dokter Fakultas Kedokteran Universitas Sam Ratulangi, Manado, Indonesia

Email: arselinacindy95@gmail.com

\begin{abstract}
The concept of self-directed learning (SDL) develops rapidly in distance education. This independent learning can be assessed by measuring the score of self-directed learning readiness (SDLR). The Medical Undergraduate Program of Faculty of Medicine Sam Ratulangi University uses the problem based learning (PBL) method which requires students to be able to study independently. The SDLR score of students is very important in the first year of study, therefore, the students will be evaluated by the institution immediately, as well as encouraging them to adapt the independent learning method. This study was aimed to obtain the description of SDLR score in the first-year students of Medical Undergraduate Program of Faculty of Medicine, Sam Ratulangi University. This was a descriptive study with a cross sectional design. The study was conducted on the first year students by using the SDLR questionnaire of Fisher modified by Nyambe. The results showed that a total of 109 students (69.87\%) had high SDLR score, 44 students $(28.2 \%)$ had moderate score, and three students (1.92\%) had low score. In conclusion, most of the first year students of Medical Undergraduate Program Faculty of Medicine, Sam Ratulangi University had high SDLR scores.
\end{abstract}

Keywords: self directed learning readiness (SDLR); medical education

\begin{abstract}
Abstrak: Konsep belajar mandiri atau self directed learning (SDL) berkembang pesat pada pendidikan jarak jauh. Pembelajaran mandiri ini dapat dinilai dengan mengukur skor self directed learning readiness (SDLR). Program Studi Pendidikan Dokter (PSPD) Fakultas Kedokteran Universitas Sam Ratulangi menggunakan metode problem based learning (PBL) yang menuntut mahasiswa untuk dapat belajar mandiri. Skor SDLR dari mahasiswa sangat penting pada tahun pertama pendidikan agar dapat segera dievaluasi oleh institusi dan untuk mendorong mahasiswa agar dapat menyesuaikan dengan metode belajar mandiri. Penelitian ini bertujuan untuk mengetahui gambaran SDLR pada mahasiswa tingkat pertama Program Studi Pendidikan Dokter (PSPD) di Fakultas Kedokteran Universitas Sam Ratulangi. Jenis penelitian ialah deskritif dengan desain potong lintang. Penelitian ini dilakukan pada mahasiswa tingkat pertama dengan menggunakan kuesioner SDLR dari Fisher yang dimodifikasi oleh Nyambe. Hasil penelitian mendapatkan 109 mahasiswa $(69,87 \%)$ mempunyai skor SDLR tinggi, 44 mahasiswa $(28,2 \%)$ dengan skor sedang, dan 3 mahasiswa $(1,92 \%)$ skor rendah. Simpulan penelitian ini ialah sebagian besar mahasiswa tingkat pertama PSPD Fakultas Kedokteran Universitas Sam Ratulangi mempunyai skor SDLR tinggi.
\end{abstract}

Kata kunci: self directed learning readiness (SDLR); pendidikan kedokteran

\section{PENDAHULUAN}

Konsep belajar mandiri merupakan konsep yang berkembang pada bidang pendidikan orang dewasa, baik pendidikan informal maupun formal. Selain dibidang pendidikan orang dewasa, konsep belajar mandiri atau self directed learning (SDL) berkembang pesat pada bidang pendidikan 
jarak jauh. Bahkan, konsep belajar mandiri seringkali dianggap identik dengan konsep belajar jarak jauh. Pemahaman tersebut muncul karena belajar jarak jauh membutuhkan kemampuan belajar mandiri yang tinggi dari peserta didik yang mengikuti program belajar jarak jauh. ${ }^{1}$

Kurikulum Berbasis Kompetensi (KBK) merupakan suatu kurikulum yang telah banyak digunakan oleh Fakultas Kedokteran di Indonesia. Kurikulum KBK digunakan sejak tahun 2007 di Fakultas Kedokteran Universitas Sam Ratulangi Manado. Kurikulum Berbasis Kompetesi sendiri menggunakan strategi belajar problem based learning (PBL) yaitu salah satu metode yang bersifat Student Centered Learning (SCL). Pembelajaran mandiri yang dinilai dengan self directed learning readiness (SDLR) sangat penting dalam pendidikan kedokteran. Dalam suatu penelitian yang dilakukan pada mahasiswa pendidikan sarjana kedokteran tentang SDLR, didapatkan mahasiswa tingkat pertama memiliki nilai SDLR yang tinggi, mereka sudah mampu menerapkan SDL dengan baik dan bila semakin lama terpapar dengan kurikulum PBL selama proses pendidikan, maka di akhir tahap pendidikan sarjana kedokteran diharapkan mahasiswa telah menjadi lebih mandiri. ${ }^{2}$

Meity $^{3}$ melaporkan bahwa hasil SDLR mahasiswa Fakultas Kedokteran di Asia pada tahun 2017 masih rendah, terutama pada mahasiswa tingkat pertama, sedangkan memasuki tingkat ketiga mereka telah belajar beradaptasi dan memahami keuntungan hal tersebut untuk dirinya. Pengukuran nilai SDLR yang dilakukan pada mahasiswa Fakultas Kedokteran di Amerika Utara mendapatkan nilai SDLR yang lebih tinggi dari rerata nilai populasi dewasa. Hasil tersebut sangat berbeda dengan yang didapatkan pada mahasiswa kedokteran di Asia dimana nilai SDLR di awal masuk masih rendah tetapi kemudian mengalami peningkatan saat memasuki tingkat ketiga.

Menurut $\mathrm{Ramli}^{4}$ beberapa penelitian melakukan pengukuran SDLR pada mahasiswa Program Studi Sarjana Kedokteran Universitas Tadulako (Untad), yang salah satu diantaranya bertujuan untuk melihat hubungan SDLR dengan prestasi belajar yang difokuskan pada mahasiswa tingkat pertama. Hasil penelitian tersebut menunjukkan bahwa terdapat hubungan antara SDLR dengan prestasi belajar mahasiswa. Mahasiswa tingkat pertama mempunyai Indeks Prestasi Kumulatif (IPK) yang kurang dibandingkan dengan hasil IPK mahasiswa tingkat kedua dan ketiga.

Metode SCL merupakan suatu sistem pembelajaran yang berpusat pada mahasiswa sehingga mereka menjadi aktif dan mandiri, mampu mengukur batas kemampuan belajar mereka, serta bertanggung jawab sepenuhnya atas pembelajarannya. 5-7 Sampai saat ini belum pernah dilaporkan penelitian mengenai SDLR di Program Studi Pendidikan Dokter Fakultas Kedokteran Universitas Sam Ratulangi. Hal ini mendorong penulis untuk melakukan evaluasi nilai SDLR pada mahasiswa tingkat pertama Fakultas Kedokteran Universitas Sam Ratulangi agar dapat menjadi bahan masukan bagi pihak pimpinan Fakultas Kedokteran Universitas Sam Ratulangi.

\section{METODE PENELITIAN}

Penelitian ini merupakan jenis deskriptif yang menggunakan instrumen penelitian kuesioner SDLR oleh Fisher dimodifikasi oleh Nyambe dengan desain potong lintang. Tujuan penelitian ialah untuk mengetahui gambaran nilai/skor SDLR pada mahasiswa tingkat pertama Fakultas Kedokteran Universitas Sam Ratulangi. Responden penelitian ini ialah mahasiswa tingkat pertama Fakultas Kedokteran Universitas Sam Ratulangi, Manado.

\section{HASIL PENELITIAN}

Berdasarkan hasil penelitian didapatkan $156(95,1 \%)$ mahasiswa sebagai responden dari populasi sebanyak 164 orang. Pada karakteristik responden berdasarkan jenis kelamin didapatkan wanita lebih banyak dari pada pria, yaitu 114 responden wanita $(72,6 \%)$ dan 43 responden pria $(27,4 \%)$.

Karakteristik responden berdasarkan usia didapatkan rentang usia 16-20 tahun, dengan usia terbanyak yaitu 18 tahun sebanyak 89 responden $(57,05 \%)$. 
Sesuai dengan kuesioner SDLR terdapat tiga aspek yang dinilai yaitu, manajemen diri, keinginan belajar, dan kontrol diri. Tabel 1 memperlihatkan nilai rerata tertinggi ialah aspek manajemen diri $(48,82)$ dan nilai rerata terendah ialah aspek kontrol diri $(42,35)$. Untuk aspek manajemen diri didapatkan skor terendah 14 , dan skor tertinggi 63 dengan skor maksimal yang bisa dicapai mahasiswa ialah 65 . Nilai rerata ialah 48,82 dengan standar deviasi 6,55. Hasil penelitian aspek keinginan belajar mendapatkan skor terendah 12 dan skor tertinggi 59 dengan skor maksimal yang bisa dicapai mahasiswa ialah 60 . Nilai rerata ialah 45,75 dengan standar deviasi 6,22 . Hasil penelitian untuk aspek kontrol diri mendapatkan skor terendah 11 dan skor tertinggi 53 dengan skor maksimal yang bisa dicapai mahasiswa ialah 55. Nilai rerata ialah 42,35 dengan standar deviasi 5,61.

Tabel 2 memperlihatkan bahwa setelah batasan skor untuk kategorisasi diperoleh maka kelompok yang memiliki kategori SDLR tinggi pada mahasiswa Program Studi Pendidikan Dokter pada tingkat pertama sebanyak 109 responden $(71,15 \%)$, kategori SDLR sedang sebanyak 44 responden $(28,2 \%)$, dan kategori SDLR rendah sebanyak 3 responden $(1,92 \%)$.

\section{BAHASAN}

Seseorang yang berhasil dalam proses pembelajaran SDLR ialah seseorang yang memiliki inisiatif, mandiri, dan gigih dalam belajar dan bertanggung jawab atas pembelajarannyasendiri. ${ }^{4,5,7}$ Wiley mendefinisikan self-directed learning readiness (SDLR) sebagai tingkatan dari sikap, keterampilan, dan karakteristik personal dari seseorang yang diperlukan untuk SDL. ${ }^{8}$ Leatemia $^{9}$ menyatakan bahwa pembelajaran mandiri dapat diartikan sebagai siswa mampu mengontrol suatu proses pembelajaran mereka sendiri dengan menggunakan perencanaan, implementasi, pemantauan, dan evaluasi. Mahasiswa mengidentifikasikan kebutuhan belajar mereka berdasarkan masalah yang dihadapi dalam proses pembelajaran. Dalam hal ini mereka mampu merumuskan tujuan belajar mereka sendiri, dan kemudian mampu menerjemahkan ke dalam suatu tujuan tertentu. Menurut Indira ${ }^{10}$ terdapat faktorfaktor yang memengaruhi kemampuan SDLR seseorang, yaitu faktor di dalam dirinya (internal) dan faktor dari luar dirinya (eksternal.) Faktor internal antara lain jenis kelamin, usia, intelegensi, pendidikan, dan faktor sosialisasi sedangkan faktor eksternal antara lain waktu belajar, tempat belajar, motivasi belajar, pola asuh orang tua, dan aksesibilitas sumber belajar.

Menurut Surbakti, ${ }^{11}$ SDLR adalah kesiapan mahasiswa terhadap lingkungan belajarnya dan kemandirian yang menuntut mahasiswa untuk belajar.

Tabel 1. Skor aspek manajemen diri, keinginan belajar, dan kontrol diri

\begin{tabular}{lccccc}
\hline Aspek SDLR & Rerata & SD & $\begin{array}{c}\text { Skor } \\
\text { Terendah }\end{array}$ & $\begin{array}{c}\text { Skor } \\
\text { Tertinggi }\end{array}$ & $\begin{array}{c}\text { Skor } \\
\text { maksimal }\end{array}$ \\
\hline Manajemen diri & 48,82 & 6,55 & 14 & 63 & 65 \\
\hline Keinginan belajar & 45,75 & 6,22 & 12 & 59 & 60 \\
\hline Kontrol diri & 42,35 & 5,61 & 11 & 53 & 55 \\
\hline
\end{tabular}

Tabel 2. Hasil perhitungan kategorisasi skala SDLR

\begin{tabular}{lccc}
\hline Batasan Skor & Kategori & Responden & Persentase (\%) \\
\hline Skor $\geq 132$ & Tinggi & 109 & 69,87 \\
\hline Skor $84-131$ & Sedang & 44 & 28,2 \\
\hline Skor $<84$ & Rendah & 3 & 1,92 \\
\hline
\end{tabular}


SDLR menerapkan pembelajaran dewasa dan menganggap diri self directed secara keseluruhan. Masalah ditanggapi dengan menggunakan pengetahuan, belajar secara proaktif, bertanggung jawab dan mampu mengambil inisiatif untuk belajar sendiri. 11,12

Prestasi belajar yang dicapai seorang siswa merupakan hasil interaksi antara berbagai faktor internal maupun faktor eksternal individu. Pengenalan terhadap faktorfaktor yang memengaruhi prestasi belajar penting sekali artinya dalam membantu mahasiswa dalam mencapai prestasi belajar yang sebaik-baiknya. Kedua faktor tersebut saling memengaruhi dalam proses belajar mahasiswa sehingga menentukan kualitas hasil belajar. ${ }^{6}$

Faktor internal ini terbagi tiga yaitu faktor jasmaniah, faktor psikologis, dan faktor kelelahan. ${ }^{6}$ Faktor jasmaniah terdiri atas kesehatan dan cacat tubuh. Setiap calon mahasiswa yang akan menyiapkan diri untuk mengikuti program studi pendidikan di Universitas Sam Ratulangi terlebih lagi di Fakultas Kedokteran harus menjalani tes kesehatan yang dengan sendirinya menyingkirkan adanya cacat tubuh. Terdapat tujuh faktor yang tergolong ke dalam faktor psikologis serta dapat memengaruhi proses belajar, yaitu: intelegensi, perhatian, minat, bakat, motivasi, kematangan, dan kesiapan. Calon mahasiswa yang diterima di Program Studi Pendidikan Dokter Fakukltas Kedokteran Universitas Sam Ratulangi harus melalui seleksi yang ketat dengan daya saing tinggi sehingga mereka yang berhasil lolos telah memenuhi standar psikologis yang dibutuhkan oleh seorang mahasiswa. Kelelahan pada seseorang walaupun sulit untuk dipisahkan tetapi dapat dibedakan menjadi dua macam, yaitu kelelahan jasmani dan kelelahan rohani. Pada mahasiswa yang sehat, adanya kelelahan jasmani akan dapat ditanggulangi dengan mengatur pola hidup yang sehat. Dengan melihat tingginya minat calon mahasiswa untuk diterima di Fakultas Kedokteran Universitas Sam Ratulangi, maka diasumsikan bahwa mahasiswa dengan minat tinggi akan dapat mengatasi kelelahan rohani yang mungkin terjadi.
Berdasarkan hasil pengolahan data didapatkan $156(95,1 \%)$ mahasiswa sebagai responden dari populasi mahasiswa sebanyak 164 orang, dengan jumlah responden wanita $(72,6 \%)$ lebih banyak daripada responden pria $(27,4 \%)$. Walaupun biasanya wanita dinilai lebih konsisten daripada pria dan mempunyai kemampuan intelektual lebih tinggi dilihat dari prestasi sekolah, ${ }^{10}$ namun tiga responden yang mendapatkan skor SDLR rendah pada penelitian ini berjenis kelamin wanita. Karakteristik responden berdasarkan usia didapatkan rentang usia 16-20 tahun. Usia terbanyak yang didapatkan yaitu 18 tahun $(57,05 \%)$ karena responden penelitian ini merupakan mahasiswa Program Studi Pendidikan Dokter pada tingkat tahun pertama. Usia yang lebih tua biasanya dinilai lebih berpengalaman, serta memiliki kemampuan dan kemauan dalam menjalani proses belajar dengan metode SDLR. ${ }^{10}$ Demikian pula dengan kemajuan aksesbilitas dalam proses pembelajaran sangat menyokong kesempatan keberhasilan proses SDLR pada mahasiswa.

Sesuai dengan kuesioner SDLR terdapat tiga aspek yang dinilai yaitu, manajemen diri, keinginan belajar dan kontrol diri. Berdasarkan hasil penelitian untuk aspek manajemen diri didapatkan, skor terendah 14, dan skor tertinggi 63 dengan skor maksimal yang bisa dicapai mahasiswa ialah 65. Nilai rerata yang diperoleh ialah 48,82 dengan standar deviasi 6,55. Berdasarkan nilai rerata jawaban responden terhadap pertanyaan pada aspek manajemen diri, pernyataan nomor dua dari kuesioner merupakan pilihan dengan nilai rerata paling tinggi $(4,17)$, yaitu tentang menentukan prioritas pekerjaan. Pernyataan nomor tiga pada kuesioner merupakan pilihan dengan nilai rerata paling rendah $(3,33)$, yaitu tentang mengatur waktu yang baik.

Berdasarkan hasil penelitian untuk aspek keinginan belajar didapatkan skor terendah 12, dan skor tertinggi 59 dengan skor maksimal yang bisa dicapai mahasiswa ialah 60 dikarenakan pertanyaan pada aspek ini berjumlah 12 pertanyaan. Nilai rerata ialah 45,75 dengan standar deviasi 6,22. 
Pada aspek keinginan belajar, pernyataan nomor 12 pada kuesioner merupakan pilihan dengan skor tertinggi $(4,26)$, yaitu tentang keterbukaan terhadap ide baru. Pernyataan nomor 16 pada kuesioner merupakan pilihan dengan skor terendah $(3,27)$, yaitu tentang mempunyai percaya diri yang tinggi terhadap kemampuan sendiri.

Berdasarkan hasil penelitian untuk aspek kontrol diri didapatkan skor terendah 11 dan skor tertinggi 53 dengan skor maksimal yang bisa dicapai mahasiswa ialah 55 dikarenakan pertanyaan pada aspek ini berjumlah 11 pertanyaan. Nilai rerata 42,35 dengan standar deviasi 5,61. Pada aspek kontrol diri, pernyataan nomor 17 pada kuesioner merupakan pilihan dengan skor tertinggi $(4,19)$, yaitu tentang sadar terhadap keterbatasan diri. Pernyataan nomor 18 pada kuesioner merupakan pilihan dengan skor terendah $(3,49)$, yaitu tentang kepercaan diri yang sangat tinggi terhadap kemampuan diri mencari informasi.

Hasil penelitian ini menunjukkan bahwa sebagian besar total skor SDLR mahasiswa program pendidikan dokter pada tingkat pertama di Fakultas Kedokteran Universitas Sam Ratulangi Manado berada pada kategori tinggi yaitu berjumlah 109 responden $(69,87 \%)$, kategorisasi SDLR sedang sebanyak 44 responden $(28,2 \%)$, dan kategorisasi SDLR rendah sebanyak tiga responden $(1,92 \%)$. Hal menarik yang didapatkan pada penelitian ini yaitu hanya tiga responden $(1,92 \%)$ yang masuk pada kategori SDLR rendah. Skor tertinggi yang dicapai ialah 172 dibandingkan skor terendah hanya 37 , dengan rerata 136,85 , dan standar deviasi 17,5.

Hasil penelitian ini tidak sejalan dengan penelitian yang dilakukan pada mahasiswa kedokteran di Asia dimana nilai SDLR di awal masuk universitas masih rendah tetapi kemudian mengalami peningkatan saat memasuki tingkat ketiga. ${ }^{3}$ Demikian pula dengan hasil penelitian tentang hubungan SDLR dan prestasi belajar mahasiswa Program Studi Kedokteran Universitas Tadulako yaitu SDLR mempunyai hubungan dengan nilai IPK (Indeks Prestasi Kumulatif), sehingga didapatkan SDLR dan rerata
IPK yang rendah pada mahasiswa tingkat pertama. Mahasiswa tingkat pertama mempunyai rerata IPK 2,22 yang lebih rendah dibandingkan nilai rerata IPK pada angkatan 2013. ${ }^{4}$

Skor SDLR yang tinggi pada sebagian besar mahasiswa tingkat pertama (angkatan 2020) dapat dipengaruhi oleh karena telah diterapkannya kurikulum 2013 (K-13) sejak tahun ajaran 2013/2014 pada sekolah di tingkat dasar sampai menengah. Walaupun belum semua sekolah dapat langsung menerapkannya saat itu namun beberapa sekolah sudah mulai melakukan adaptasi dan pada tahun ajaran 2019/2020 semua sekolah sudah diwajibkan oleh Kementerian Pendidikan dan Kebudayaan untuk menggunakan kurikulum 2013 ini. Salah satu keunggulan dari kurikulum 2013 ini ialah bahwa siswa dituntut untuk lebih aktif, kreatif dan inovatif dalam setiap pemecahan masalah yang mereka hadapi di sekolah. Metode yang diterapkan pada sekolah-sekolah sama seperti metode PBL yang telah diterapkan di Fakultas Kedokteran Sam Ratulangi sejak tahun 2007, sehingga dapat dilihat bahwa sebagian besar mahasiswa tingkat pertama telah siap dalam metode belajar mandiri.

Menurut Yustiana ${ }^{13}$ manajemen diri ialah mengelola diri, bagaimana kita dapat dan harus mengelola diri sehingga menjadi diri yang sehat, efektif, dan produktif. Untuk hasil manajemen diri berdasarkan hasil penelitian ini dijelaskan bahwa skor rerata kemampuan manajemen diri mahasiswa yang memiliki SDLR tinggi lebih besar dari pada mahasiswa dengan SDLR rendah. Dalam hal ini ditunjukkan bahwa kemampuan manajemen diri mahasiswa yang memiliki SDLR tinggi lebih baik dibandingkan mahasiswa dengan SDLR rendah.

Mahasiswa yang mandiri mampu untuk mengontrol dirinya sendiri seperti minat, sikap dan usaha terhadap proses belajar tanpa dipengaruhi oleh dosen, teman atau orang tua. Mahasiswa yang memiliki SDLR tinggi mempunyai kesadaran dari dalam diri sendiri sehingga dapat bertanggung jawab terhadap dirinya dan mengontrol proses belajarnya dengan baik. Menurut Goldfried kontrol diri diartikan sebagai kemampuan 
untuk menyusun, membimbing, mengatur dan mengarahkan bentuk perilaku yang dapat membawa ke arah konsekuensi positif. ${ }^{14}$

Dari hasil penelitian didapatkan bahwa keinginan belajar mahasiswa mempunyai kemauan atau keinginan belajar yang tinggi dengan skor tertinggi 59. Keinginan belajar merupakan suatu kerangka mental yang terdiri dari kombinasi gerak perpaduan dan campuran dari perasaan dan kecenderungan lain yang biasa mengarahkan individu kepada suatu pilihan tertentu. ${ }^{15}$ Berdasarkan nilai rerata pada tiap pertanyaan dalam aspek keinginan belajar, dapat disimpulkan bahwa sebagian besar mahasiswa sangat terbuka terhadap ide-ide yang baru sehingga mempunyai kecenderungan untuk mempelajari hal-hal baru, namun kurang percaya diri terhadap kemampuan diri sendiri. Kurangnya percaya diri pada kemampuannya sendiri juga tergambar dalam aspek kontrol diri, sehingga perlu adanya kegiatan fakultas, atau dorongan para dosen pembimbing akademik, penanggung jawab semester, tim modul, pakar, tutor, atau instruktur skill lab yang dapat meningkatkan percaya diri mahasiswa terhadap kemampuannya.

Keunggulan penelitian ini ialah jumlah responden yang tinggi yaitu sebanyak $95,1 \%$ dari jumlah populasi. Selain itu, penelitian ini merupakan yang pertama tentang SDLR di Program Studi Pendidikan Dokter Fakultas Kedokteran Universitas Sam Ratulangi.

Keterbatasan penelitian ini ialah pada data responden tidak dapat dilihat nama dan email responden yang mengirimkan jawaban, sehingga peneliti tidak dapat memberikan masukan atau motivasi secara individual bagi responden yang memiliki nilai SDLR yang rendah agar bisa meningkatkan nilai SDLR responden tersebut.

\section{SIMPULAN}

Sebagian besar mahasiswa tingkat pertama Fakultas Kedokteran Universitas Sam Ratulangi mempunyai skor SDLR tinggi.

\section{Konflik Kepentingan}

Penulis menyatakan tidak terdapat konflik kepentingan dalam studi ini.

\section{DAFTAR PUSTAKA}

1. Darmayanti T. Readiness for self-directed learning and achievement of the students of Universitas Terbuka (The Indonesian Open Learning University). Tesis master yang tidak dipublikasikan, University of Victoria, Victoria, BC. (1994).

2. Sadiqin AF. Hubungan motivasi belajar dengan tingkat self directed learning readiness (SDLR) pada mahasiswa pendidikan sarjana kedokteran angkatan 2013 di Universitas. Malahayati. Jurnal Ilmu Kedokteran dan Kesehatan. 2016;3(1). Available from: http://ejurnal malahayati.ac.id/index.php/kesehatan/a rticle/view/725

3. Meity N. Penerapan self directed learning melalui sistem PBL pada mahasiswa fakultas kedokteran di Asia. Jurnal Pendidikan Kedokteran Indonesia. 2017; 6(3):133-9. Available from: https://jurnal.ugm.ac.id/jpki/article/vie w/32227Meity.

4. Ramli. Pengaruh self directed learning readiness terhadap prestasi akademik mahasiswa FKIK Untad. Available from: http://repository.sb.ipb.ac.id/3137/5/E2 2K-05-Ramli-Pendahuluan.pdf.

5. Savannah A. Hubungan motivasi belajar dengan selfdirected learning readiness pada mahasiswa kedokteran tahun per tama Fakultas Kedokteran Univer-sitas Andalas. Available from: http://scholar. unand.ac.id/55119/

6. Slameto. Faktor-faktor yang mempengaruhi proses belajar. 2013. Available from: https://www.coursehero.com/file/pqrt5 9v/Slameto-2013-Belajar-dan-Faktor-

Faktor-yang-MempengaruhinyaJakarta-Rineka/

7. Knowles M. Self-directed learning: A guide for learners and teachers. Chicago: Follett Publishing Company, 1975.

8. Wiley K, Effect of a self-directed learning project and preference for structure on self-directed learning readiness. Nurs Res. 1983;32(3):181-5.

9. Leatemia LD, Susilo AP, van Berkel H. Selfdirected learning readiness of Asian students: students perspective on a hybrid problem based learning curriculum. Int J Med Educ. 2016;3(7): 385-92

10. Sugianto IM, Lisiswanti R. Tingkat self 
directed learning readiness (SDLR) pada mahasiswa kedokteran. Medical Majority. 2016;5(5):27-31.

11. Surbakti ESB. Hubungan motivasi belajar terhadap self directed learning readiness mahasiswa Fakultas Kedokteran Universitas Lampung. J Agromedicine. 2019;6(1):139-44.

12. Nyambe H, Harsono, Rahayu GR. Faktorfaktor yang mempengaruhi self directed learning readiness pada mahasiswa tahun pertama, kedua dan ketiga di Fakultas Kedokteran Universitas Hassanuddin dalam PBL. Jurnal Pendidikan Kedokteran, 2016;5(2):67-75.

13. Yustiana YR. Psikologi dan bimbingan. Available from: http://file.upi.edu/
Direktori/FIP/JUR._PSIKOLOGI_PEN D_DAN_BIMBINGAN/19661115199 1022-YUSI_RIKSA_YUSTIANA/ SAP\%2C_RPP/

14. Majid AN. Hubungan kontrol diri (selfcontrol) dengan prokrastinasi akademik dalam menyelesaikan skripsi pada mahasiswa FTIK. Available from: http://e-repository.perpus.iainsalatiga. ac.id/1636/1/ahklis1.pdf

15. Riadi M. Minat belajar (pengertian, unsur, jenis, indikator, dan cara menumbuhkan. Available from: https://www. kajianpustaka.com/2020/05/minatbelajar-pengertian-unsur-jenisindikator-dan-cara-menumbuhkan.html 